\title{
AGOSTINHO: RUMO A UMA RAZÃO AFETIVA
}

\author{
Mariana Paolozzi Sérvulo da Cunha \\ Universidade Federal de Santa Catarina
}

Resumo: 0 objetivo deste artigo é caracterizar a razão agostiniana a fim de demarcar 0 significado da filosofia para Agostinho e a racionalidade com a qual opera. A razão sempre acompanha-se, de modo indissociável, da vontade/amor; nesse sentido podemos nos referir a ela como uma razão afetiva. Pretende-se apenas trazer à luz importante aspecto do pensamento agostiniano, por meio de alguns textos que permitam fundamentar e esboçar a ideia de uma 'razão afetiva', expressão, aliás, não empregada por Agostinho, mas que, a nosso ver, traduz muito de seu pensamento: a intelecção exige vontade/amor.

Palavras-chave: Agostinho, razão afetiva, conhecimento, vontade, amor

Abstract: This articles analyzes reason in Augustine's thought with a view to demarcating his conception of philosophy and rationality. As for this author reason is inextricably associated with will/love, we claim that it can be understood as an affectionate reason. Even though he himself does not use this term, we present evidence that it manages to capture the meaning of a recurring, key idea in his works: intellection requires will/love.

Keywords: Augustine, affectionate reason, knowledge, will, love

O objetivo deste artigo é caracterizar a razão agostiniana a fim de demarcar o significado da filosofia para Agostinho e a racionalidade com a qual opera. Em Agostinho a razão divide sua primazia, na alma, com a memória e a vontade/amor. Não aprofundaremos aqui o significado e papel da memória, ao menos está claro que não há intelecção sem o seu uso, mas o enfoque será posto na relação da razão com a vontade/amor visto não haver, também, intelecção sem vontade/amor. 
Por que mais exatamente uma razão afetiva? Diferentemente do intelectualismo grego, o papel da vontade/amor, em Agostinho, é tão predominante quanto o da razão. ${ }^{1}$ Melhor dizendo, a razão sempre acompanha-se, de modo indissociável, da vontade/amor; nesse sentido podemos nos referir a ela como uma razão afetiva. A razão, juntamente com a vontade/amor, e a memória, são consideradas por Agostinho a essência da alma. $^{2}$ Como veremos adiante, todo amor é uma vontade intensa, e toda vontade implica um amor em potencial, daí a associação vontade/amor.

É um tanto imprudente abordar esse tema de modo breve, porém pretende-se apenas trazer à luz importante aspecto do pensamento agostiniano, por meio de alguns textos que permitam fundamentar e esboçar a ideia de uma 'razão afetiva', expressão, aliás, não empregada por Agostinho, mas que, a nosso ver, traduz muito de seu pensamento: a intelecção exige vontade/amor. Os termos razão, vontade e amor fazem parte de nosso vocabulário corrente, mas é preciso se precaver contra problemas de homonímia e de generalização. Inicialmente serão apresentados alguns esclarecimentos sobre a razão e amor, em seguida sobre a vontade.

Ratio e amor possuem em Agostinho, conforme o contexto, significados variados, como também são empregados diversos vocábulos para se lhes referir. Por exemplo, a razão às vezes é adjetivada como superior, ou inferior conforme sua função (a inferior dirige-se ao mundo sensível, a superior, ao inteligível), e também é empregada, em alguns contextos, como sinônimo de intellegentia ou spiritus. Nessa acepção a razão é aquilo, no ser humano, que lhe é único e individual (marca de sua 'pessoalidade') e o que possui de mais elevado, aquilo por meio do que conhecemos as coisas, conforme discutido anteriormente.

O amor, por sua vez, também possui gama variada de significados, conforme o contexto e o termo que o defina. Agostinho utiliza-se de três vocábulos para referi-lo: charitas, dilectio e amor. Em De civitate Dei XIV, 6, defende o uso desses três termos como sinônimos:

De quem tem propósito de amar a Deus e ao próximo como a si mesmo, não segundo o homem, mas segundo Deus, se diz ser de boa vontade por esse amor. Nas Sagradas Letras o nome mais

\footnotetext{
${ }^{1}$ Sobre a importância da vontade e sua relação com a razão ver: BERMON, E. Le cogito dans la pensée de Saint Augustin. Paris: Vrin, 2001; CUNHA, M. P. S. O movimento da alma: a invenção por Agostinho do conceito de vontade. Porto Alegre: Edipucrs, 2001.

${ }^{2} \mathrm{~A}$ respeito do significado preciso dessa afirmação, ver a discussão da imagem de Deus no ser humano, em, por exemplo A Trindade I. X e XIV-XV.
} 
corrente de tal afeto é o de caridade, mas chamam-no também de amor... Julguei-me no dever de recordar tudo isso precisamente por alguns pensarem que uma coisa é dileção ou caridade e outra o amor. Dizem dever-se tomar em bom sentido a dileção e em mau o amor... Já mostramos que a palavra "amor" também se usa em bom sentido.

Apesar dessa afirmação, encontramos em algumas passagens da obra agostiniana uma variação no emprego dessa terminologia. Por exemplo, na questão 35 (De diversis quaestionibus $83,35,2$ ), escrita durante os anos 388-395/6 (portanto anteriormente ao De civitate Dei, do ano 413), as palavras charitas e dilectio são reservadas, preferivelmente, ao amor bom: "Amor autem rerum amandarum, charitas vel dilectio melius dicitur".

Visto haver amores bons, também haveria amores maus, e levando em conta que amor e charitas podem ser considerados termos correspondentes, deve haver, também, caridades boas ou más; todavia, apenas excepcionalmente Agostinho falará em caridades ilícitas.

E, por fim, para concluir essas observações terminológicas, apesar dos três termos citados poderem se corresponder, o vocábulo amor seria o mais adequado para se referir ao amor do bem e do mal; o termo dilectio, apesar de aludir também ao amor desregrado, seria reservado para designar mais exclusivamente o amor ao bem ("omnis dilectio, sive quae carnalis dicitur, quae non dilectio, sed magis amor dici solet (dilectionis enim nomen magis solet in melioribus rebus dici, in melioribus accipi"), In Epist. Joan. ad Parthos, VIII, 5). ${ }^{3}$

Usualmente o amor é tido por nós como sentimento, afeto. Em a Cidade de Deus vimos Agostinho empregando o termo afectus para referilo. No entanto, sendo incorporal, o amor também é considerado substância ou espírito, sentido inusual para nós (De trin. IX, II, 2: "Et si aliqua substantia est amor, non est utique corpus sed spiritus...", ver também XI, $\mathrm{V}, 9)$.

O amor humano é substancial por participar da estabilidade da natureza divina, mas dela se diferencia por estar em movimento. Essas são importantes características de um pensamento centrado em revelações bíblicas do gênero: "Deus é amor"," "Deus é espírito". Ao longo de sua vida Agostinho meditou sobre essas temáticas, buscando formas e

${ }^{3}$ GILSON, E. Introduction á L'Étude de saint Augustin. Paris: Vrin, 1982, p. 177, nota 2.

$41 \mathrm{Jo} 4,8$.

${ }^{5} \mathrm{~S} J 04,24$. 
expressões próprias que mostrassem o significado e alcance desses ensinamentos cristãos.

Feitas essas observações preliminares a fim de contextualizar a discussão, passemos à indissociabilidade da razão com o amor: o forjar de uma 'razão afetiva', seu significado e funcionamento.

Basicamente procuraremos descrever a razão afetiva através da explicação sobre o amor e sua finalidade, isso nos permitirá apreender seu modus essendi et operandi. $\mathrm{O}$ amor requer e visa o conhecimento. Só podemos amar aquilo que, se não conhecemos totalmente, ao menos em parte conhecemos; no entanto, por si só, o amor não tem a capacidade de conhecer. Assim, para sua realização, depende da razão e é auxiliado por ela. Mas o amor também, conforme Agostinho, almeja a fruição e a posse do que é amado. Partiremos então para o aprofundamento da discussão do amor e sua realização em seus componentes indispensáveis: fruição, posse, conhecimento.

Posteriormente serão analisados os papéis da vontade/amor em algumas etapas do processo de aquisição de conhecimento. Procurar-se-á também explicitar o sentido da asserção 'conhecer completamente é amar e amar completamente é conhecer', a partir da advertência de que é preciso esvaziar essa fórmula de sentimentalismo. Após o exame dessas questões, e para finalizar, a discussão se voltará, brevemente, à influência da razão afetiva na ação humana.

$\mathrm{O}$ amor, em um de seus aspectos, é considerado uma vontade mais forte, a vontade em toda sua força ("...voluntatem nostram, vel amorem seu dilectionem quae valentior est voluntas" - "...a nossa vontade ou nosso amor ou dileção, que é a mesma vontade com força maior"). ${ }^{6}$

Onde há vontade existe um amor em potencial. Se todo amor é vontade intensa, nem toda vontade é amor. A vontade pode não se transformar em amor, mas todo amor origina-se dela: é sempre uma vontade/amor (o amor sempre provém da vontade). Eis porque, ao falar sobre o amor, será preciso compreender a vontade.

Ao atingir aquilo que é desejado, a vontade, convertendo-se em amor, encontra quietude e desfruta daquilo que é amado. Quando a vontade, transformada em amor, atinge seu fim, alcança complacência (satisfação). $\mathrm{O}$ itinerário da vontade e do amor é singular e próprio a cada pessoa, configurando, assim, a vida individual. Se, por um lado, a vontade sempre anseia fruir, o amor, por sua vez, é fruição.

${ }^{6}$ De Trin. XV, XXI, 41. 
Mas, para Agostinho, além da fruição, o objetivo do amor está ligado ao conhecimento e à posse. Ressaltando, o amor exige três elementos imprescindíveis: fruição, conhecimento e posse do que é amado. Como lemos em De diversis quaestionibus $(83,35,2)$, a finalidade do amor é "conhecer e possuir algo de eterno". Importa, porém, esclarecer o significado da afirmação. Conforme dito, o vínculo do amor com o conhecimento pode ser facilmente constatado, na medida em que só podemos amar (ou apetecer) aquilo que conhecemos, ao menos parcialmente. Todavia, se uma finalidade do amor é conhecer, não é propriamente o amor quem conhece (ele não está dotado dessa capacidade), mas sim a razão, associada ao amor - a razão afetiva. Novamente, só podemos amar aquilo que conhecemos e esse conhecimento é operacionalizado por meio da razão. Completando a explicação de Agostinho sobre o objetivo do amor: conhecer e possuir o transitório não basta à satisfação humana, pois tudo que não é permanente pode ser subtraído do amor, apenas o eterno não pode ser tomado do amor ("Aeternum est enim, de quo solo recte fiditur, quod amanti auferri non potest”; ibidem). De modo que, se a finalidade do amor também é fruição, nem tudo deve ser objeto do amor (único meio de evitar a perda do que é amado). ${ }^{7}$

Dizer que é necessário querer amar e conhecer somente o bem que não pode nos fazer falta enquanto amamos e conhecemos (posse), é dizer que antes de tudo deve-se amar aquilo que sempre está presente, é referir-se à plena ordenação do amor (ordo amoris): esse bem é acima de tudo Deus. Em outras palavras, o que não pode ser tomado do amor e sempre está presente é Deus, que, por não ser matéria, apenas é possuído enquanto conhecido, isto é, só é possuído pelo conhecimento. ${ }^{8}$

Entretanto, se só conhecemos aquilo que nos é presente (ou fisicamente ou presente à nossa razão e memória), e se, respeitando a ordo amoris, devemos antes de tudo amar aquilo que sempre está presente (isto é, Deus), por outro lado podemos também nos recusar a conhecer o que se apresenta a nós. $\mathrm{O}$ ato do conhecimento é essencialmente volitivo: eis a força da razão afetiva.

Não cabe aqui desenvolver, em poucas linhas, a abrangente temática do conhecimento de Deus como finalidade do amor, esparsa ao longo da obra agostiniana. Optamos por outra via. Dando um passo adiante na

\footnotetext{
7 Há coisas que devem ser utilizadas e outras das quais devemos fruir: o tema uti/frui encontra-se sintetizado em A doutrina cristã I, 3-4.

8 "Cujus ergo rei amor amandus est, nisi ejus quae non potest deesse dum amatur? Id autem est, quod nihil est aliud habere quam nosse" (Quaestiones 83, 35).
} 
descrição de alguns aspectos da natureza e funcionamento da razão afetiva, poderíamos nos perguntar quais seriam as principais etapas do processo de aquisição de conhecimento, que por si mesmas expressam a intrínseca relação entre a razão e o amor.

Nesse sentido importa esclarecer de que modo a concepção agostiniana de razão vincula-se indissociavelmente à noção de amor e nos remete à concepção do bem (razão/amor/bem). No processo de aquisição de conhecimento, a articulação desses termos é clara para Agostinho, pois só podemos conhecer plenamente aquilo que amamos e esse conhecimento ("amoroso") implica em saber quão bom é um bem: "Todavia, ninguém pode ter ou conhecer completamente um bem que não é amado. Quem pode conhecer o quanto é bom aquilo de que não frui? Porém, não frui se não ama..." .

Para Agostinho, o mundo, como criação, ${ }^{10}$ é concebido como um conjunto de bens (há, no entanto, os bens máximos, médios e mínimos). Conhecer um bem implica saber o quanto é bom: conhecer é reconhecer um bem, e sabemos que é um bem - isto é, o quanto é bom - fruindo dele; em outras palavras, amando-o. Eis porque é possível falar em uma razão afetiva. A razão tem como alvo o conhecimento, e, para Agostinho, conhecer plenamente é amar (se o amor é o conhecimento de quão bom é um bem, conhecer nada mais é do que saber, fruindo, o quanto um bem é bom). Logo, pode-se dizer que o objetivo da razão, o conhecimento, é o amor (ou: 'conhecimento total é amor'). [888]

Tomemos a asserção 'conhecer completamente é amar'. ${ }^{11}$ É possível invertê-la sem prejuízo de significado: "conhecer completamente é amar (é saber quão bom é um bem)" e "amar completamente é conhecer (é saber quão bom é um bem)". Chega-se aqui a uma dupla fórmula que, possuindo reciprocidade, contribui para a compreensão do modus essendi da razão afetiva. $\mathrm{O}$ conhecimento ocorre por meio da razão, enquanto amamos por meio do amor. Mas razão e amor se interrelacionam, dado que "conhecer completamente é amar, e amar completamente é conhecer". Em outras palavras, estamos falando de uma razão que juntamente com o amor, ama, isto é, conhece; e um amor que, juntamente com a razão, conhece

\footnotetext{
${ }_{9}^{9}$ Quaestiones 83, 35: "Quanquam bonum quod non amatur, nemo potest perfecte habere vel nosse. Quis enim potest nosse quantum sit bonum, quo non fruitur? Non autem fruitur, si non amat: nec habet igitur quod amandum est, qui non amat; etiam si amare possit, qui non habet. Nemo igitur beatam vitam novit, et miser est: quoniam si amanda est, sicuti est, hoc est eam nosse quod habere".

${ }^{10} \mathrm{~A}$ criação é entendida como a doação de ser, pelo Ser, aos seres. Estabelece-se uma relação entre 0 Bem e o Ser, e os bens e os seres.

11 Ninguém pode ter ou conhecer completamente (perfecte) um bem que não é amado. Assim, também há graus de conhecimento.
} 
(recordando: não se ama o que não se conhece). De modo que, se é possível chegar afirmar que o objetivo da razão é o amor (no sentido explicitado acima), ao longo desse estudo vimos querendo também enfatizar que a própria razão quanto a sua maneira de ser (e antes de inteligir) está atrelada à vontade/amor: não há intelecção sem vontade/amor. A razão é razão afetiva não só porque visa o amor, mas também porque em sua natureza não pode ser separada dele. A razão associada ao amor, ama; isto é conhece; por outro lado a razão sozinha, isto é, sem vontade/amor, não ama, isto é, não conhece (desiste do conhecimento). Enfim, a razão pode ser considerada razão afetiva quanto a sua essência e finalidade.

Aqui cabe uma advertência. Como apreender sem equivocar-se o sentido da asserção "conhecer completamente é amar e amar completamente é conhecer"? É necessário precaver-se contra a pieguice, e essa fórmula pode nos soar ridiculamente sentimental. $O$ contexto agostiniano, principalmente quando nos referimos ao amor e sua ligação com o conhecimento, sempre possui o pano de fundo ontológico (distante de nosso sentimentalismo).

Avancemos em nossa reflexão. Na busca do conhecimento, a razão afetiva é primordialmente impulsionada pela vontade. Ela é o impulso inicial na aquisição do conhecimento e pode desembocar no amor (como resultado), fechando-se o ciclo do processo de conhecimento. Note-se que o amor é vontade quando falta aquilo que é amado; fruição quando o que é amado está presente.

Para elucidar o que foi dito, recorramos a algumas passagens da obra De Trinitate, ${ }^{12}$ onde Agostinho discute o tema minuciosamente. Por exemplo, no processo de aquisição de conhecimento da realidade sensível, a vontade e o amor têm um papel de união, porém lhes é reservada não só essa função, mas também a de separação. Vejamos o que isso significa através da interação entre a memoria (sensibilis), a uisio (interior) e a uoluntas.

Do mesmo modo que a vontade leva o sentido (visão) em direção ao corpo quando o notamos, não estando mais o corpo presente e querendo nos lembrar dele, a vontade aplica o olhar interior do pensamento à memória, onde pode restar uma imagem do corpo. Mas a vontade, que aproxima esses termos e os une (isto é, os sentidos ao corpo, ou o olhar interior do pensamento à imagem do corpo na memória), pode ser também aquilo que os divide e separa. No caso da percepção sensível, é, por exemplo, através de um movimento do corpo que a vontade pode separar os sentidos daquilo

${ }^{12}$ Cf. I.XI,III, 6. 
que é percebido, a fim de impedir a percepção ou interrompê-la; no caso do olhar interior do pensamento e da memória (isto é, da lembrança do corpo), basta que, através da vontade, desvie-se o pensamento para algo diverso da imagem do corpo retida na memória para haver ruptura do processo cognitivo (que também ocorre por rememoração).

Resta salientar que no processo cognitivo o papel do amor, inicialmente como vontade, e depois, em uma etapa final, como fruição (o saber quão bom é um bem), ocorre apenas como uma possibilidade: esse ciclo pode ou não se concluir. Uma vez que, na aquisição do conhecimento, ao amor enquanto vontade está destinada não somente a função de unir como também a de separar, a vontade pode ou não estimular a aquisição de conhecimento pela razão.

Ao afirmar-se o vínculo do conhecimento com a vontade/amor, sobressai a originalidade de Agostinho. Ele explicita e ressalta, no campo do conhecimento, a atuação de elementos não analisados anteriormente: a vida "intelectual" constitui-se como expressão de uma razão afetiva.

E, para finalizar esta seção, assinalemos a importância da razão afetiva na ação humana. Se, por um lado, a razão isoladamente não determina os atos humanos (posso agir à revelia do que a razão me aponta como sendo o melhor), agimos através de uma razão afetiva: a vontade, ou amor, impelem a ação (não apenas a aquisição do conhecimento). $\mathrm{O}$ amor, atrelado à razão, é para Agostinho princípio de movimento do agir. Ele é o peso dos seres humanos (sua lei de gravidade), que os conduz a seus lugares:

O corpo tende, sob a ação de seu peso, em direção ao lugar que lhe é próprio. Mas seu peso não o leva forçosamente para baixo, ele vai em direção ao lugar que é seu. O fogo sobe, a pedra desce. Colocados em movimento pelo seu peso, adquirem seus respectivos lugares... Meu peso é meu amor. Para qualquer lugar que eu seja levado, é ele que me leva. ${ }^{13}$

Os elementos racionais e afetivos atuam simultaneamente no agir humano, e isso contrasta com a visão que afirma a possibilidade da primazia de uma razão soberana na determinação dos atos humanos. Conforme seus amores o ser humano dirige-se a diferentes lugares, conforme seus amores

${ }^{13}$ Conf. XIII, IX, 10. 
desenrola-se sua vida; em uma escala maior, é possível também compreender a história através deles. ${ }^{14}$

A intenção aqui foi esboçar o funcionamento e natureza da razão afetiva, suas relações com o conhecimento e com a ação humana. Em suma, se em Agostinho a filosofia implica o amor à sabedoria, ela move-se orientada por uma razão afetiva.

\section{Referências}

AUGUSTINUS, De ciuitate dei libri uiginti duo. Corpus Christianorum, Series Latina 47. Turnholt: Brepols, 1955.

. Confessionum libri XIII. Corpus Christianorum, Series Latina 27. Turnholt: Brepols, 1990.

. De diuersis quaestionibus octoginta tribus liber unus. Corpus Christianorum, Series Latina 44A. Turnholt: Brepols, 1975.

. De doctrina christiana libri quattuor. Corpus Christianorum, Series Latina 32. Turnholt: Brepols, 1990.

. De trinitate libri quindecim. Corpus Christianorum, Series Latina 50-50A. Turnholt: Brepols, 1968.

AGOSTINHO, Santo. Cidade de Deus. São Paulo: Vozes, 1990.

Pensadores).

. Confissões. São Paulo: Abril Cultural, 1973. (Col. Os . A doutrina cristã. São Paulo: Paulus, 2002.

. A Trindade. São Paulo: Paulus, 1995.

BERMON, E. Le cogito dans la pensée de Saint Augustin. Paris: Vrin, 2001.

CUNHA, M. P. S. O movimento da alma: a invenção por Agostinho do conceito de vontade. Porto Alegre: Edipucrs, 2001.

GILSON, E. Introduction á L'Étude de saint Augustin. Paris: Vrin, 1982.

Email: marianapaolozzi1@gmail.com

Recebido: 05/2013

Aprovado: 02/2014

\footnotetext{
${ }^{14} \mathrm{Em}$ a Cidade de Deus Agostinho discorre sobre o surgimento de duas cidades, conforme dois amores (XIV, 28): 0 amor próprio funda a cidade terrena, e o amor a Deus a celestial. Esta busca a glória a Deus, e a primeira a glória dos indivíduos.
} 